\title{
MIPAS detects Antarctic stratospheric belt of NAT PSCs caused by mountain waves
}

\author{
M. Höpfner ${ }^{1}$, N. Larsen ${ }^{2}$, R. Spang ${ }^{3}$, B. P. Luo ${ }^{4}$, J. Ma ${ }^{5}$, S. H. Svendsen ${ }^{2}$, S. D. Eckermann ${ }^{6}$, B. Knudsen ${ }^{2}$, \\ P. Massoli ${ }^{7, *}$, F. Cairo ${ }^{7}$, G. Stiller ${ }^{1}$, T. v. Clarmann ${ }^{1}$, and H. Fischer ${ }^{1}$ \\ ${ }^{1}$ Forschungszentrum Karlsruhe, Institut für Meteorologie und Klimaforschung, Karlsruhe, Germany \\ ${ }^{2}$ Danish Meteorological Institute, Middle Atmosphere Research Division, Copenhagen, Denmark \\ ${ }^{3}$ Forschungszentrum Jülich, Institut für Chemie und Dynamik der Geosphäre, Jülich, Germany \\ ${ }^{4}$ Institut für Atmosphäre und Klima, ETH-Hönggerberg, Zürich, Switzerland \\ ${ }^{5}$ Computational Physics, Inc., Springfield, VA, USA \\ ${ }^{6}$ E. O. Hulburt Center for Space Research, Naval Research Laboratory, Washington, USA \\ ${ }^{7}$ Consiglio Nazionale delle Ricerche, Istituto di Scienze dell'Atmosfera e del Clima, Rome, Italy \\ * now at: University of Colorado, Cooperative Institute for Research in the Environmental Sciences, Boulder, CO, USA
}

Received: 19 July 2005 - Published in Atmos. Chem. Phys. Discuss.: 26 October 2005

Revised: 3 February 2006 - Accepted: 15 February 2006 - Published: 20 April 2006

\begin{abstract}
Space borne infrared limb emission measurements by the Michelson Interferometer for Passive Atmospheric Sounding (MIPAS) reveal the formation of a belt of polar stratospheric clouds (PSCs) of nitric acid trihydrate (NAT) particles over Antarctica in mid-June 2003. By mesoscale microphysical simulations we show that this sudden onset of NAT PSCs was caused by heterogeneous nucleation on ice in the cooling phases of large-amplitude stratospheric mountain waves over the Antarctic Peninsula and the Ellsworth Mountains. MIPAS observations of PSCs before this event show no indication for the presence of NAT clouds with volume densities larger than about $0.3 \mu \mathrm{m}^{3} / \mathrm{cm}^{3}$ and radii smaller than $3 \mu \mathrm{m}$, but are consistent with supercooled droplets of ternary $\mathrm{H}_{2} \mathrm{SO}_{4} / \mathrm{HNO}_{3} / \mathrm{H}_{2} \mathrm{O}$ solution (STS). Simulations indicate that homogeneous surface nucleation rates have to be reduced by three orders of magnitude to comply with the observations.
\end{abstract}

\section{Introduction}

Nearly twenty years ago, the important role of polar stratospheric clouds (PSCs) in polar ozone depletion began to be appreciated (Solomon et al., 1986; Toon et al., 1986; Crutzen and Arnold, 1986). In addition to the activation of chlorine from its reservoirs $\mathrm{HCl}$ and $\mathrm{ClONO}_{2}$, PSCs can remove $\mathrm{NO}_{\mathrm{y}}$ i.e. total odd nitrogen defined as the sum $\mathrm{NO}+\mathrm{NO}_{2}+\mathrm{NO}_{3}+2 \mathrm{~N}_{2} \mathrm{O}_{5}+\mathrm{HNO}_{3}+\mathrm{HO}_{2} \mathrm{NO}_{2}+\mathrm{ClONO}_{2}+$

Correspondence to: $\mathrm{M}$. Höpfner

(michael.hoepfner@imk.fzk.de)
$\mathrm{BrONO}_{2}$ from the lower stratosphere by incorporation of $\mathrm{HNO}_{3}$ from the gas phase and subsequent sedimentation. This denitrification leads to a slower conversion of active chlorine back to $\mathrm{ClONO}_{2}$.

In the Antarctic winter, Tabazadeh et al. (2000) have shown that denitrification occurs before significant dehydration. In the Arctic vortex, Fahey et al. (2001) discovered large nitric acid containing particles (likely nitric acid trihydrate, NAT) that, via sedimentation, are now generally believed to be the major cause of denitrification.

However, the nucleation processes of nitric acid hydrate PSCs still remain unclear (Tolbert and Toon, 2001). Three possible processes have been discussed: heterogeneous nucleation on ice particles, homogeneous freezing of particles of supercooled ternary $\mathrm{H}_{2} \mathrm{SO}_{4} / \mathrm{HNO}_{3} / \mathrm{H}_{2} \mathrm{O}$ solutions (STS), and heterogeneous freezing induced by solid material other than ice.

There is a wealth of evidence for the nucleation of nitric acid hydrate particles on ice from observations of mountain wave PSCs over the Scandinavian mountain ridge and the east coast of Greenland (Carslaw et al., 1998; Wirth et al., 1999; Tsias et al., 1999; Rivière et al., 2000; Voigt et al., 2000; Larsen et al., 2002b; Dörnbrack et al., 2002; Hu et al., 2002; Voigt et al., 2003; Luo et al., 2003; Fueglistaler et al., 2003; Reichardt et al., 2004; Eckermann et al., 2006). Modelling by Carslaw et al. (1999) indicated that mountain waves were a significant source of solid nitric acid-containing particles on a synoptic scale in the Arctic, persisting thousands of kilometres downstream of the wave event that formed them. These clouds, which consist of a large number of

Published by Copernicus GmbH on behalf of the European Geosciences Union. 


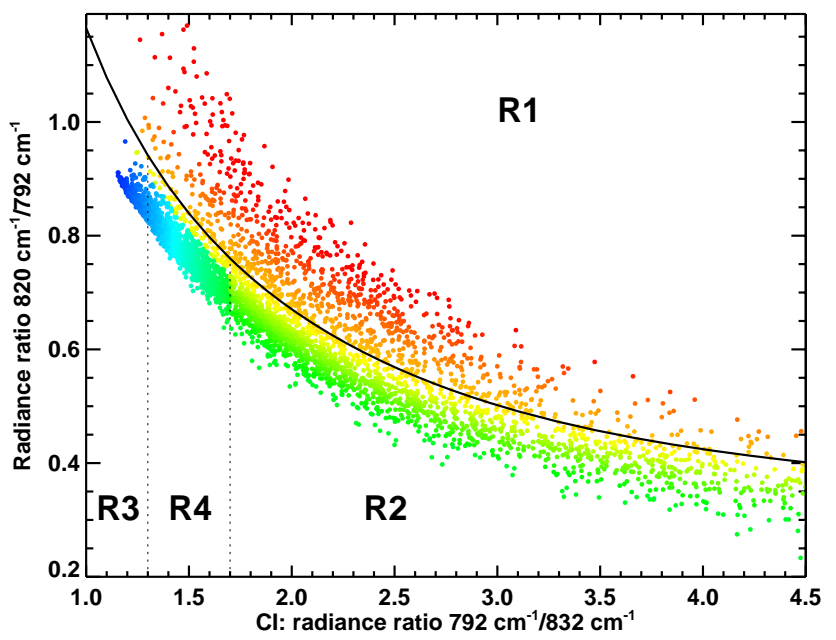

Fig. 1. Mean spectral intensity in the interval $819-821 \mathrm{~cm}^{-1}$ (I $\left.\left[819-821 \mathrm{~cm}^{-1}\right]\right)$ divided by I[788.2-796.25 $\left.\mathrm{cm}^{-1}\right]$ versus I[788.2-796.25 $\left.\mathrm{cm}^{-1}\right] / \mathrm{I}\left[832.3-834.4 \mathrm{~cm}^{-1}\right]$ of MIPAS PSC observations in May/June 2003 for tangent altitudes between 16 and $25 \mathrm{~km}$. The colour scale of the data points denotes their relative position with respect to the different regions in the plot and is used to describe MIPAS measurements and simulations in the following figures.

relatively small particles, may lead to the formation of progressively larger NAT particles and subsequent denitrification through a mechanism proposed by Dhaniyala et al. (2002) and Fueglistaler et al. (2002). Recently, using parameterizations based on this scheme, Mann et al. (2005) showed that a large part of the air with temperatures below the NAT threshold can be populated with particles sedimented from these clouds. Such "mother cloud" NAT growth and sedimentation processes (Fueglistaler et al., 2002) could account for up to $80 \%$ of the observed denitrification in their model simulations of the 1999/2000 Arctic winter.

Despite the evidence for NAT formation through heterogeneous nucleation on ice, there are observations which cannot be explained by this process (Pagan et al., 2004; Irie et al., 2004; Larsen et al., 2004; Voigt et al., 2005) and, thus, require freezing mechanisms operating above the ice frost point.

Tabazadeh et al. (2001) predicted a "polar freezing belt" forming at temperatures of 190-192 K around the edges of Antarctica at $20 \mathrm{~km}$ altitude on the basis of homogeneous nucleation of nitric acid trihydrate (NAT) or nitric acid dihydrate (NAD) from STS. The magnitude of the applied freezing rates, however, have been disputed by Knopf et al. (2002) which has been rebutted by Tabazadeh (2003). Tabazadeh et al. (2002) proposed a surface-based homogeneous nucleation from reanalysis of laboratory data. Using this process measured amounts of denitrification in the Arctic stratosphere could be reproduced (Irie et al., 2004). However, Larsen et al. (2004) parameterized this surface based mech- anism in modelling of early PSC observations over northern Scandinavia in December 2002. They found that a reduction of the freezing rates by a factor of 10-20 was necessary to produce agreement with the observations. Calculations by Svendsen et al. (2005) indicate that lidar observations of PSCs in the Arctic winter 1999/2000 can best be reproduced by a combination of mountain wave-induced and homogeneous NAT formation. During the same winter, Drdla and Browell (2004) argued that neither volume nor surface dependent homogeneous freezing can reproduce observed PSC development and denitrification. They concluded that another freezing mechanism, such as heterogeneous freezing on solid impurities, was needed to explain early solid phase formation. This is in agreement with Voigt et al. (2005) who explained their observations of $\mathrm{HNO}_{3}$ containing solid particles formed at low supersaturations by heterogeneous nucleation on meteoritic dust.

In this paper we analyze hemispheric PSC measurements by the Michelson Interferometer for Passive Atmospheric Sounding (MIPAS) on Envisat (Fischer and Oelhaf, 1996; ESA, 2000). MIPAS is a limb-sounder which measures the mid-infrared spectral radiance emitted by the constituents of the Earth's atmosphere with high spectral resolution and covering a broad spectral range. MIPAS measurements continuously monitor PSCs throughout the polar stratosphere even at night.

Spang et al. (2005) describe MIPAS PSC observations during the Arctic winter 2002/2003. MIPAS also probed the development of PSCs over Antarctica in 2003 quasi continuously apart from 19-20 May, 25 May-4 June and 5-7 September when no measurements were available. In the present study we concentrate on MIPAS observations in May and June 2003 to investigate the initial phases of PSC formation in the Antarctic polar stratosphere.

\section{Identification of PSC composition}

In a companion paper, Höpfner et al. (2006) demonstrate how the composition of PSCs can be inferred from MIPAS spectra. In particular a prominent spectral band at around $820 \mathrm{~cm}^{-1}$ facilitates detection of NAT particles. Höpfner et al. (2006) show that unambiguous identification of NAT and ice observations is possible by use of a colour-ratio method introduced by Spang et al. (2001a,b, 2002); Spang and Remedios (2003); Spang et al. (2004). Comparisons between PSCs simultaneously measured by MIPAS and a ground-based aerosol lidar at McMurdo station during 2003 reveal consistent correlations between NAT, STS, and ice composition identified by MIPAS and Type 1a, Type $1 \mathrm{~b}$ and Type 2 PSCs, respectively, identified in lidar aerosol backscatter and depolarization.

Figure 1 plots colour-ratios for all the MIPAS PSC observations over Antarctica during May/June 2003. The different regions R1-R4 represent the typical colour-ratio classes 

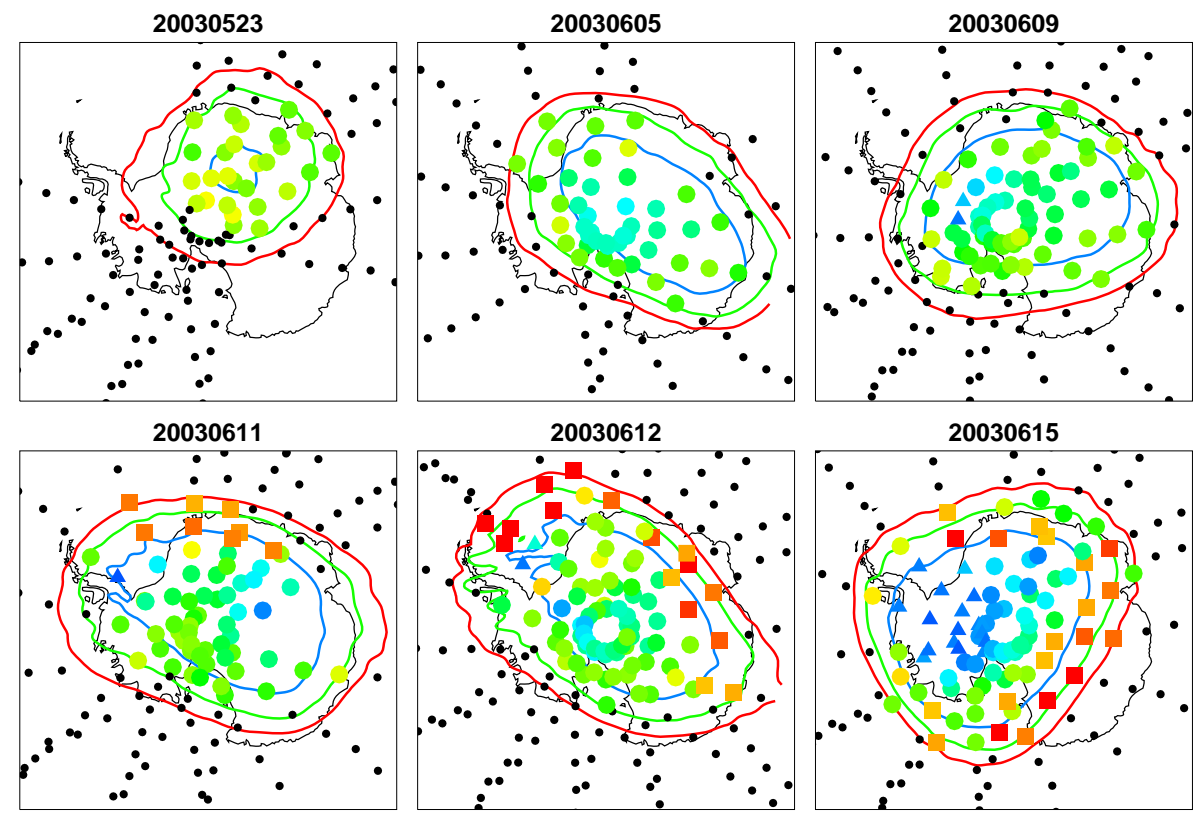

Fig. 2. Distribution of PSC types derived from MIPAS measurements at tangent altitudes corresponding to potential temperatures around $490 \mathrm{~K}$ (max. range 460-525 K), i.e. around $21 \mathrm{~km}$ altitude. The colour scale of the data points is defined as in Fig. 1: red/orange squares are NAT particles with radii $<3 \mu \mathrm{m}$, blue triangles are ice and blue-green circles are probably STS, but could also be NAT particles with radii $>3 \mu \mathrm{m}$ or thin ice clouds. The contour lines are based on ECMWF analyses and enclose the ice existence region in blue, the STS region in green and the NAT region in red. Black dots are PSC-free observations.

which have been assigned to different PSC compositions (Höpfner et al., 2006). R1 contains NAT particles with mean radii smaller than $3 \mu \mathrm{m}$. Ice PSCs are located in R3. R2 data are most likely STS, but large NAT or thin ice layers cannot be excluded. In R4 it is difficult to distinguish among ice, STS and large NAT. The colour scale of the data points in Fig. 1 is used in the plots to depict the location of each measurement or model result on this colour-ratio graph.

\section{The Antarctic NAT belt}

We have used MIPAS observations in May and June 2003 to investigate the initial phases of PSC formation in the Antarctic polar stratosphere. Figure 2 shows the geographical distribution of PSCs at an altitude of around $21 \mathrm{~km}$ for selected days. PSCs were first observed on 21 May. On that day and during the following period until 10 June, there is no sign of NAT particles. (No MIPAS data were acquired from 25 May until 4 June so we cannot exclude NAT formation during this period. However, the McMurdo Lidar detected no solid particles during a PSC observation on 2 June.) The PSC maps at these times are populated with blue-green colour-ratios of region R2 in Fig. 1, and thus appear to be mostly STS. The green contour in Fig. 2 shows the STS formation threshold temperature, derived from European Centre for MediumRange Weather Forecasts (ECMWF) analysis. It is remarkable how well the region of detected PSCs is enclosed within this area of possible STS existence defined by this temperature contour. There are very few PSCs detected between the NAT and the STS threshold temperature contours in Fig. 2.

On 10 June (not shown) there is the first clear evidence for NAT in one MIPAS limb-scan east of the Antarctic Peninsula. From Fig. 2 we see that on 11 June MIPAS observed an extended zone of NAT between $45^{\circ} \mathrm{W}$ and $45^{\circ} \mathrm{E}$ at latitudes of about $70^{\circ} \mathrm{S}$. On 12 June, a belt of NAT particles has formed that surrounds half of the Antarctic continent, extending to a length of about $7000 \mathrm{~km}$. On 15 June this NAT belt is nearly closed right around the continent. Throughout the rest of the winter, NAT PSCs were present in MIPAS observations throughout the polar vortex and often were the most abundant type of PSC.

We have investigated this sudden onset of NAT PSCs over Antarctica during 10-12 June. It is striking that NAT first appeared slightly downstream of the Antarctic Peninsula (Fig. 2), while upstream of the Peninsula there was no evidence for any PSCs despite very similar synoptic stratospheric temperatures. Further, nearby and slightly east of the coastline of the Peninsula, ice was observed on 11 and 12 June in regions which correlate with an oscillatory structure in the frost point contours based on temperatures from the ECMWF analysis. Such structure was probably due to some explicitly-resolved long-wavelength gravity waves in the analysis.

Since gravity waves are poorly resolved in global analyses (Hertzog et al., 2002; Fueglistaler et al., 2003; Eck- 

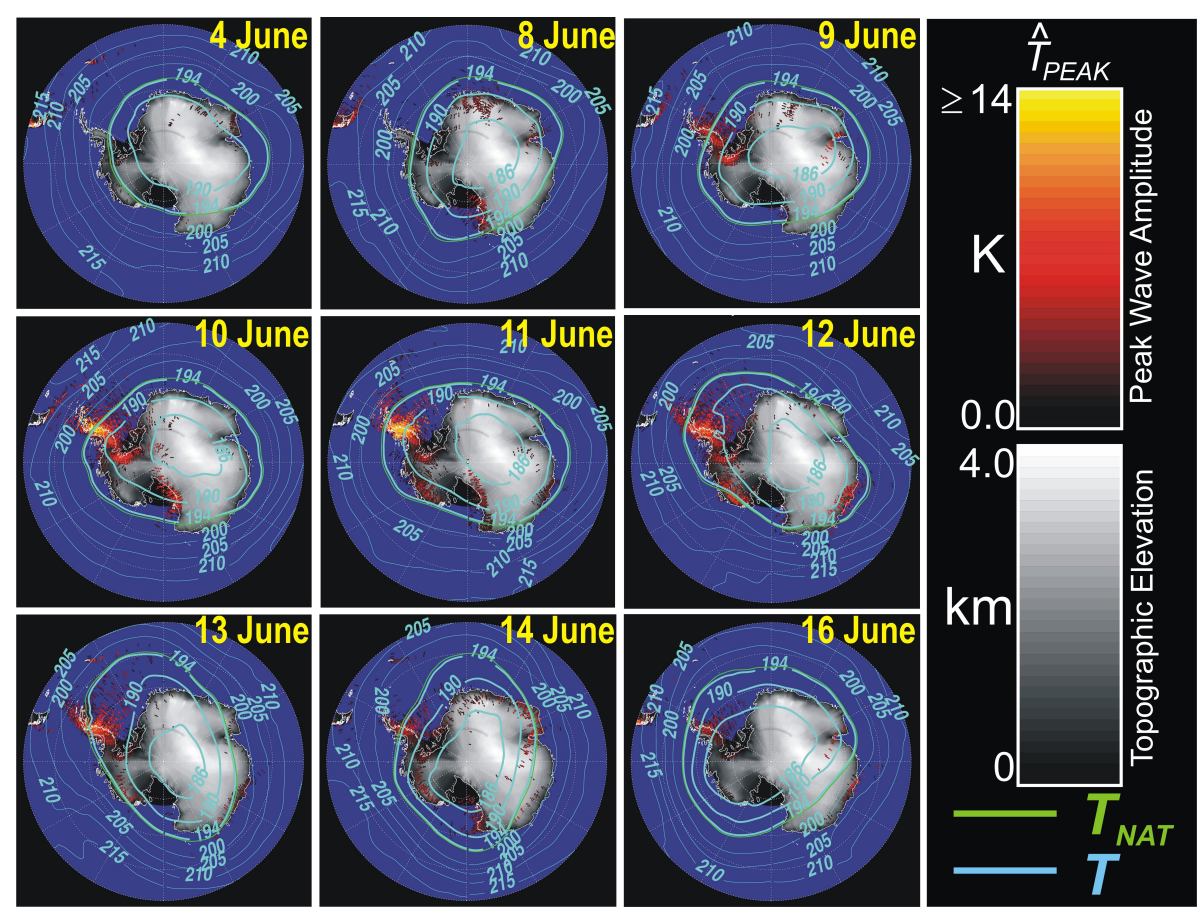

Fig. 3. MWFM-2 hindcast of peak mountain wave temperature amplitudes at $40 \mathrm{hPa}$ for various days in June 2003 at $12 \mathrm{Z}$, based on $1.25^{\circ} \times 1^{\circ}$ 36-level analyses from NASA's Global Modeling and Assimilation Office. Blue contours show synoptic temperatures, green contour shows the local NAT formation temperature based on a calculation using 10 ppbv of $\mathrm{HNO}_{3}$ and 5 ppmv of $\mathrm{H}_{2} \mathrm{O}$.
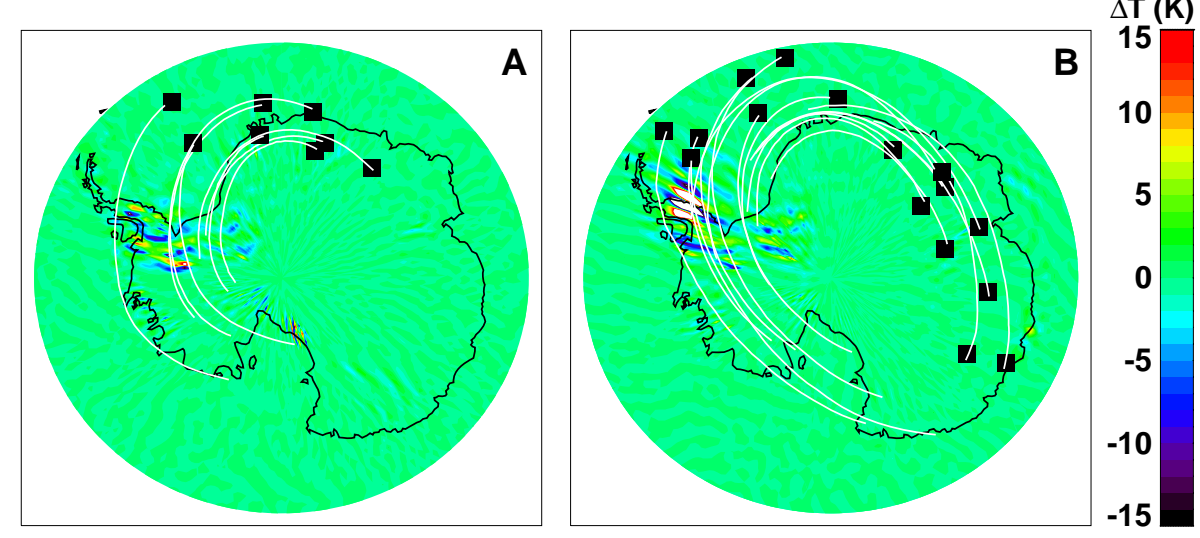

Fig. 4. Colour-coded MWFM-3 hindcast mountain-wave temperature perturbations for 12:00 UT on 10 June (A) and 12:00 UT on 11 June (B). Overlaid backward trajectories (white lines) start at the times and locations of MIPAS NAT observations (squares) on 11 June (A) and 12 June (B) and end at 00:00 UT on 10 June (A) and 00:00 UT on 11 June (B). Note that the MWFM-2 solutions in Fig. 3 show peak wave amplitudes only, whereas the MWFM-3 runs in this figure provide both amplitude and phase.

ermann et al., 2006), we have assessed the mountain wave contribution using the Naval Research Laboratory Mountain Wave Forecast Models (MWFM). The simulations were performed using both the standard validated version 2 spatial ray model (Eckermann and Preusse, 1999; Jiang et al., 2004), and a developmental next-generation version 3 model based on the high-resolution Fourier-ray solution method of Brout- man et al. (2003): see Eckermann et al. (2005a) ${ }^{1}$. These codes are hereafter referred to as MWFM-2 and MWFM$3 \beta$, respectively. The Fourier-ray MWFM- $3 \beta$ dynamical core offers significant advantages over MWFM-2, including

\footnotetext{
${ }^{1}$ Eckermann, S. D., Broutman, D., Ma, J., and Lindeman, J.: Fourier-ray modeling of short wavelength trapped lee waves observed in infrared satellite imagery near Jan Mayen, Mon. Wea. Rev., in review, 2005a.
} 
use of unsimplified high-resolution topography, correction of spatial ray caustics, direct simulation of wave phase, full free and trapped wave solutions, and more accurate wave action (amplitude) solutions (Eckermann et al., 2005 $\mathrm{a}^{1}$ ). For the MWFM- $3 \beta$ runs centred over Antarctica we used a $2048 \times 2048$ point Cartesian mesh centred over the South Pole with a $6 \times 6 \mathrm{~km}$ horizontal resolution and $0.5 \mathrm{~km}$ vertical resolution from the surface up to $30 \mathrm{~km}$ altitude. To include a realistic geographical variation in wind and temperature profiles across the domain, we subdivided this domain into $12 \times 12$ (144) component subdomains each of $170 \times 170$ grid points. We then performed 144 separate $2048 \times 2048$ Fourier-ray calculations using the ECMWF wind and temperature profile at the centre of the specific subdomain in question for initialization. Then, only the solution within this $170 \times 170$ point subdomain was retained. Using this "jigsaw puzzle" approach, we were able to synthesize a final $2048 \times 2048$ point mountain wave solution from these 144 individual runs using the additive linear properties of Fourierray solutions, which incorporated realistic geographical variations in the wind profiles across the domain. For validation, we also conducted companion MWFM-2 runs to assess the robustness of the final results.

Figure 3 shows MWFM-2 peak ray temperature amplitudes at $40 \mathrm{hPa}$ for various days in June at 12:00 UT based on ray-tracing through an atmosphere specified by analysis from NASA's Global Modeling and Analysis Office. A strong mountain wave event over the Antarctic Peninsula starts on 9 June and lasts until 13 June with maximum peak wave amplitudes of $\sim 15 \mathrm{~K}$ on 10 and 11 June. Figure 4 shows that backward trajectories starting at the position of MIPAS NAT observations on 11 and 12 June encountered areas of strong temperature perturbations due to stratospheric mountain waves hindcast by MWFM- $3 \beta$ over the Antarctic Peninsula and Ellsworth Mountains. The lack of NAT observations before this event is consistent with the absence of strong mountain wave activity (Fig. 3).

We also simulated the observations with the Danish Meteorological Institute (DMI) microphysical PSC model (Larsen et al., 2002b) running on vortex-filling trajectories (Larsen et al., 2002a; Knudsen and Grooß, 2000) based on ECMWF analysis data. Diabatic descent along the trajectories was calculated with the ECMWF radiation scheme (Morcrette, 1991). The model was initialized with MIPAS high latitude mean values of $\mathrm{H}_{2} \mathrm{O}$ and $\mathrm{HNO}_{3}$ from 17 May, a few days before the first PSCs were observed by MIPAS. Simulations started on 16 May. The model output of particle size distributions for NAT, STS, and ice at each measurement time and location was used to simulate the limb-radiances that would be detected by MIPAS in the spectral regions used for the colour-ratio plots in Fig. 1. These calculations were performed with the Karlsruhe Optimized and Precise Radiative transfer Algorithm (KOPRA). KOPRA has been used in previous studies to simulate MIPAS measurements of PSCs (Höpfner et al., 2002; Höpfner, 2004) and has been validated in Höpfner and Emde (2004). For STS, refractive indices of Biermann et al. (2000) have been used. Compositions were calculated for thermodynamic equilibrium (Carslaw et al., 1994) based on ECMWF temperature analysis, 0.3 ppbv of $\mathrm{H}_{2} \mathrm{SO}_{4}$, and high-latitude mid-May mean profiles for $\mathrm{H}_{2} \mathrm{O}$ and $\mathrm{HNO}_{3}$ from MIPAS. The latter two have been derived with the scientific MIPAS processor at IMK. The retrieval procedure for $\mathrm{H}_{2} \mathrm{O}$ has been described by Milz et al. (2005) and for $\mathrm{HNO}_{3}$ by Mengistu Tsidu et al. (2005). NAT observations have been simulated with the refractive indices derived from Biermann (1998) as described in Höpfner et al. (2006) and ice has been simulated using the data of Toon et al. (1994).

The DMI model results, which have been colour-coded in the same manner as the observations, are shown in Fig. 5 for the model run using ECMWF temperatures without correction and including the MWFM mountain-wave temperature corrections. In these runs NAT was set to nucleate only via the ice phase. We could reproduce the NAT observations only in the case where the mountain wave temperature correction was applied. In the run where purely synoptic temperatures were used no extended area of NAT was formed.

Comparison of the observation and simulation in Fig. 5 over the central Antarctic region reveals that on 11 and 12 June the DMI PSC model produces clouds with lower values of the cloud index (darker blue) compared to the measurements. This is caused by formation of water ice PSCs in the model. The measurements, however, indicate ice confined mainly near the Antarctic Peninsula, very probably caused by the mountain wave activity there (see Fig. 3). From comparison with radiosondes a cold bias of -1 to $-3 \mathrm{~K}$ has been found in the ECMWF temperatures between 490 and $570 \mathrm{~K}$ potential temperature (P. von der Gathen, pers. comm., Höpfner et al. (2006)). Model calculations incorporating this sonde-derived correction of the ECMWF temperatures produce fewer ice PSCs and agree better with the measurements in the central vortex region (Fig. 5). A mountain waveinduced NAT belt also appears in this case, however, the correspondence with the NAT observations is somewhat worse than for the uncorrected run. We assume that this is caused by errors induced by application of a constant ECMWF temperature bias independent of geolocation. The limited radiosonde data and comparison of ECMWF temperatures with radio occultation measurements (Gobiet et al., 2005) in fact show a bias that is larger near the pole than away from the pole.

\section{Homogeneous NAT nucleation}

Due to the smooth synoptic temperature distribution preceding such a strong mountain wave event, the Antarctic polar vortex is an ideal natural laboratory to constrain NAT nucleation rates above the ice frost point $\left(\mathrm{T}_{\text {ice }}\right)$. For this purpose we performed DMI PSC model runs in which homogeneous 

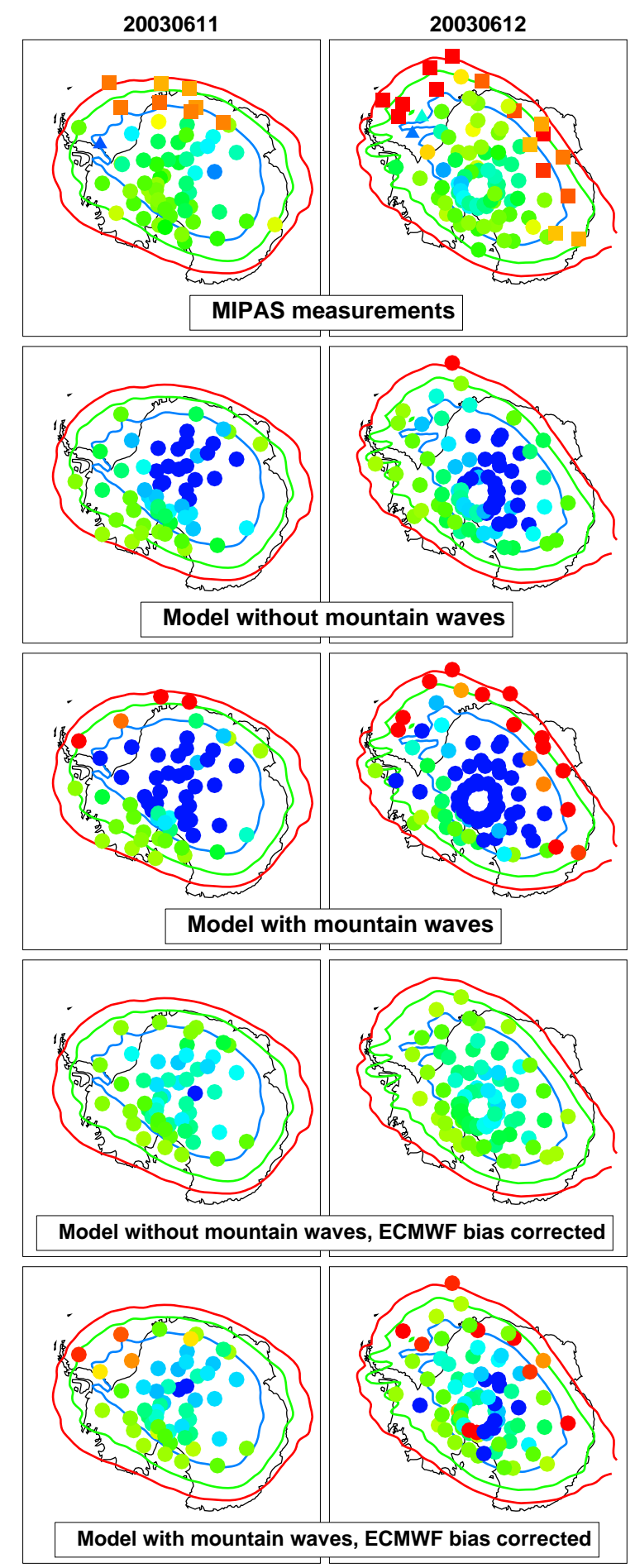

Fig. 5. MIPAS measurements on 11 and 12 June in comparison with DMI microphysical PSC box model simulations at the time and location of the observations. The colour scale is the same as in Fig. 2. In the 2nd row the ECMWF temperatures are used, whereas model runs shown in the 3rd row add the mountain wave corrections from MWFM-3. Rows 4 and 5 show equivalent runs, but on basis on ECMWF temperatures which have been corrected for a bias with respect to radiosondes (see text).

surface freezing of NAT out of liquid STS was included as representative of a size-selective nucleation mechanism at temperatures above $T_{i c e}$. Homogeneous surface dependent nucleation of NAD (Tabazadeh et al., 2002) was included in 


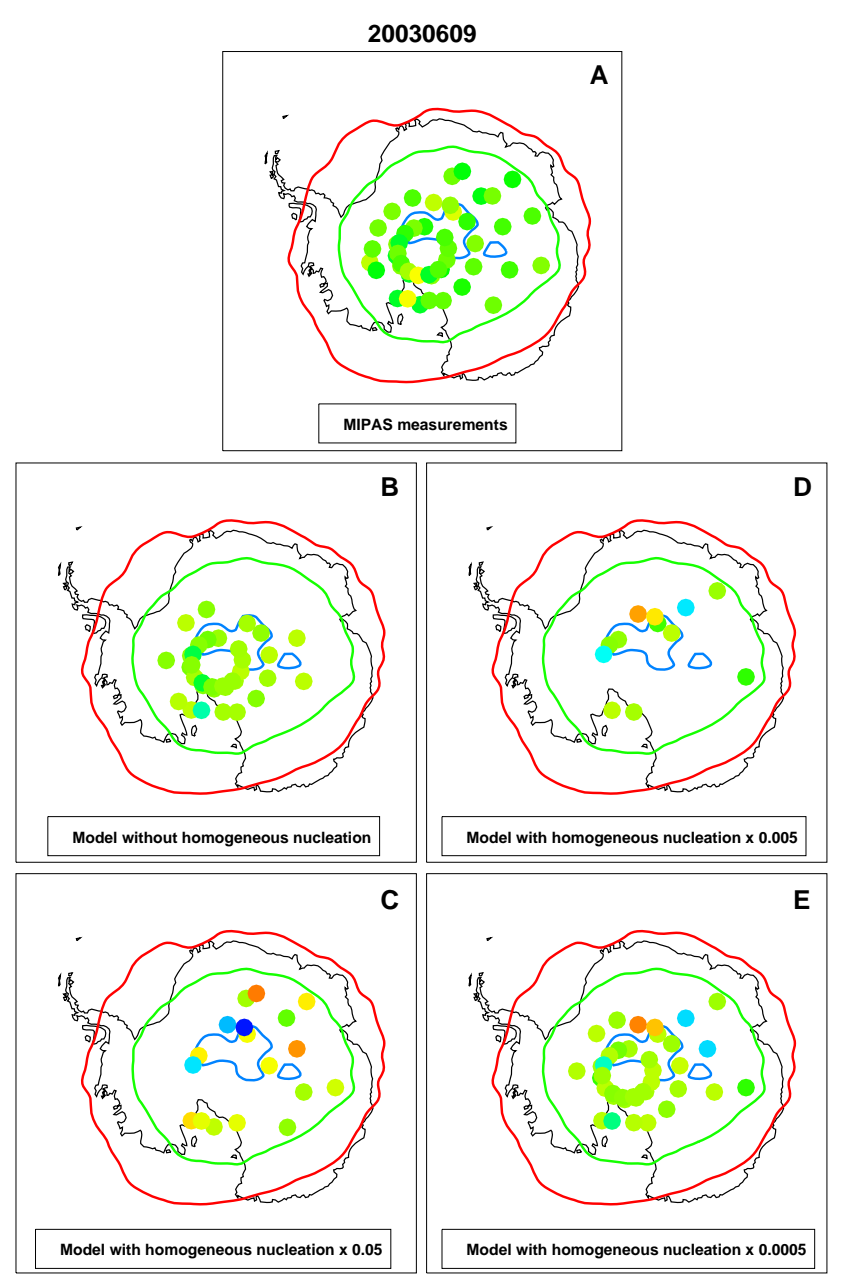

Fig. 6. MIPAS PSC observations at $570 \mathrm{~K}$ potential temperature (about $24 \mathrm{~km}$ ) on 9 June 2003 in comparison with PSC model calculations including particle sedimentation. In (B) NAT formation was possible only via the ice phase. (C-E): homogeneous surface dependent nucleation of NAD (Tabazadeh et al., 2002) assuming an instantaneous conversion of NAD to NAT is included. In (C) surface nucleation rates of (Tabazadeh et al., 2002) have been multiplied by a factor 0.05 as derived from measurements in the Arctic (Larsen et al., 2004). Further reductions are 0.005 in (D), and 0.0005 in (E). Due to effective denitrification in the model runs (C) and (D) PSC existence is strongly suppressed compared to (B) and (E). For all model runs ECMWF temperature data have been corrected for a bias with respect to radiosondes (see text). The colour scale of the data points is defined as in Fig. 1.

the model by assuming an instantaneous conversion of NAD to NAT. Various surface nucleation rates have been tested: the original rates by Tabazadeh et al. (2002) have been reduced by a factor of 20 according to Larsen et al. (2004), by 200, and by 2000 .

In the model run which is compatible with rates deduced from Arctic observations (Larsen et al., 2004) NAT PSCs appeared with particle radii $>3 \mu \mathrm{m}$ as early as 23 May. By 5 June, most of the modeled PSC region was populated with NAT PSCs, which, due to their large radius, cannot directly be distinguished from STS clouds in the MIPAS measurements using the aforementioned analysis methods. However, model results including sedimentation show that these large particles denitrify the upper PSC levels very quickly, preventing formation of extended regions of PSCs in mid-June as was seen in our observations (Fig. 6). We had to reduce the nucleation rate further (by a factor of 2000 with respect to Tabazadeh et al., 2002) to comply with the observations.

\section{Conclusions}

We could explain the sudden formation of vortex-wide areas of NAT PSCs around Antarctica during 10-12 June only by stratospheric mountain wave activity forming ice over the Antarctic Peninsula and Ellsworth Mountains. The process operating here is the same mountain wave NAT formation model originally proposed by Carslaw et al. (1999) for the Arctic winter stratosphere. Yet significant mountain waveinduced PSC formation has been largely discounted in the 
Antarctic, due to fewer mountains and colder synoptic temperatures. Nonetheless, several observational studies from the late 1980s and early 1990s also reported PSCs forming initially near the Antarctic Peninsula, then rapidly filling out greater volumes downstream (Cariolle et al., 1989; Ricaud et al., 1995). Since stratospheric mountain waves occur recurrently over the Antarctic Peninsula during winter (Wu and Jiang, 2002; Bacmeister et al., 1990), the localized mountain wave-triggering of synoptic-scale NAT belts documented here may not be a rare or even unusual event, and so may explain these earlier observations as well. This suggests a more significant role for mountain waves in Antarctic PSC formation than has heretofore been appreciated.

Our analysis of MIPAS measurements further demonstrates that the observation of denitrification before dehydration (Tabazadeh et al., 2000) in the Antarctic stratospheric vortex is not necessarily due to a freezing mechanism of NAT above the ice frost point. It can be initiated by formation of large "mother clouds" of NAT particles nucleated on ice produced by mountain wave activity early in the Antarctic winter, which denitrify the air masses through the mechanism of Dhaniyala et al. (2002) and Fueglistaler et al. (2002).

The fact that we have seen no indication for NAT in MIPAS observations before 10 June does not rule out the presence of NAT PSC particles with volume densities smaller than about $0.3 \mu \mathrm{m}^{3} / \mathrm{cm}^{3}$ or with radii larger than $3 \mu \mathrm{m}$ which are the detection limits of the colour-ratio method (Höpfner et al., 2006). Nonetheless, we could still estimate an upper limit for surface nucleation rates which is about three orders of magnitude smaller than the one proposed by Tabazadeh et al. (2002). These values are much smaller even than those derived by Larsen et al. (2004) to explain the early appearance of solid particles in December 2002 which was unusually cold (e.g. Goutail et al., 2005). A second hint for a difference in NAT nucleation between the Arctic winter 2002 and the Antarctic winter 2003 is MIPAS observations of PSCs over the Arctic in December 2002 when, contrary to our measurements over Antarctica, NAT was detected only a few days after the first PSC observation without hints of previous mountain wave activity (Spang et al., 2005; Larsen et al., 2004). Whether this possible difference in NAT nucleation rates above $T_{\text {ice }}$ between the Arctic and Antarctic is typical or related to singular events is to be assessed by future monitoring of the initial stages of PSC development.

Acknowledgements. We thank P. von der Gathen for helpful discussions. Authors of this work were supported by the German HGF-Vernetzungsfonds ENVISAT (BMBF 01SF9953/8). MIPAS spectra were provided by the European Space Agency and meteorological data by ECMWF. PSC model runs were funded by the EU project SCOUT-O3.

Edited by: A. Lambert

\section{References}

Bacmeister, J. T., Schoeberl, M. R., Lait, L. R., Newman, P. A., and Gary, B.: ER-2 mountain wave encounter over Antarctica Evidence for blocking, Geophys. Res. Lett., 17, 81-84, 1990.

Biermann, U. M.: Gefrier- und FTIR-Experimente zur Nukleation und Lebensdauer stratosphrischer Wolken, Ph.D. thesis, Universitt Bielefeld, cuvillier Verlag, ISBN 3-89712-212-X, 1998.

Biermann, U. M., Luo, B. P., and Peter, T.: Absorption spectra and optical constants of binary and ternary solutions of $\mathrm{H}_{2} \mathrm{SO}_{4}$, $\mathrm{HNO}_{3}$, and $\mathrm{H}_{2} \mathrm{O}$ in the mid infrared at atmospheric temperatures, J. Phys. Chem. (A), 104, 783-793, 2000.

Broutman, D., Rottman, J. W., and Eckermann, S. D.: A Simplified Fourier Method for Nonhydrostatic Mountain Waves., J. Atmos. Sci., 60, 2686-2696, 2003.

Cariolle, D., Muller, S., Cayla, F., and McCormick, M. P.: Mountain waves, polar stratospheric clouds, and the ozone depletion over Antarctica, J. Geophys. Res., 94, 11 233-11 240, 1989.

Carslaw, K. S., Luo, B. P., Clegg, S. L., Peter, T., Primblecombe, P., and Crutzen, P. J.: Stratospheric aerosol growth and $\mathrm{HNO}_{3}$ gas phase depletion from coupled $\mathrm{HNO}_{3}$ and water uptake by liquid particles, Geophys. Res. Lett., 21, 2479-2482, 1994.

Carslaw, K. S., Wirth, M., Tsias, A., Luo, B. P., Dörnbrack, A., Leutbecher, M., Volkert, H., Renger, W., Bachmeister, J. T., and Peter, T.: Particle microphysics and chemistry in remotely observed mountain polar stratospheric clouds, J. Geophys. Res., 103, 5785-5796, 1998.

Carslaw, K. S., Peter, T., Bacmeister, J. T., and Eckermann, S. D.: Widespread solid particle formation by mountain waves in the Arctic stratosphere, J. Geophys. Res., 104, 1827-1836, 1999.

Crutzen, P. J. and Arnold, F.: Nitric acid cloud formation in the cold Antarctic stratosphere: A major cause for springtime "ozone hole", Nature, 324, 651-655, 1986.

Dörnbrack, A., Birner, T., Fix, A., Flentje, H., Meister, A., Schmid, H., Browell, E. V., and Mahoney, M. J.: Evidence for inertia gravity waves forming polar stratospheric clouds over Scandinavia, J. Geophys. Res., 107(D20), 8287, doi:10.1029/2001JD000452, 2002.

Dhaniyala, S., Mckinney, K. A., and Wennberg, P. O.: Lee-wave clouds and denitrification of the polar stratosphere, Geophys. Res. Lett., 29, 36-1, 2002.

Drdla, K. and Browell, E. V.: Microphysical modeling of the 19992000 Arctic winter: 3. Impact of homogeneous freezing on polar stratospheric clouds, J. Geophys. Res., 109(D10), D10201, doi:10.1029/2003JD004352, 2004.

Eckermann, S. D. and Preusse, P.: Global measurements of stratospheric mountain waves from space, Science, 286, 1534-1537, 1999.

Eckermann, S. D., Dörnbrack, A., Vosper, S. B., Flentje, H., Mahoney, M. J., Bui, T. P., and Carslaw, K. S.: Mountain waveinduced polar stratospheric cloud forecasts for aircraft science flights during SOLVE/THESEO 2000, Wea. Forecasting, 21, 4268, 2006.

ESA: Envisat MIPAS: An instrument for atmospheric chemistry and climate research, Tech. Rep. SP-1229, European Space Agency, SA Publications Division, ESTEC, P. O. Box 299, 2200 AG Noordwijk, The Netherlands, 2000.

Fahey, D. W., Gao, R. S., Carslaw, K. S., Kettleborough, J., Popp, P. J., Northway, M. J., Holecek, J. C., Ciciora, S. C., McLaughlin, R. J., Thompson, T. L., Winkler, R. H., Baumgardner, D. G., 
Gandrud, B., Wennberg, P. O., Dhaniyala, S., McKinney, K., Peter, T., Salawitch, R. J., Bui, T. P., Elkins, J. W., Webster, C. R., Atlas, E. L., Jost, H., Wilson, J. C., Herman, R. L., Kleinböhl, A., and von König, M.: The Detection of Large $\mathrm{HNO}_{3}$-Containing Particles in the Winter Arctic Stratosphere, Science, 291, 10261031, 2001.

Fischer, H. and Oelhaf, H.: Remote sensing of vertical profiles of atmospheric trace constituents with MIPAS limb-emission spectrometers, Appl. Opt., 35, 2787-2796, 1996.

Fueglistaler, S., Luo, B. P., Voigt, C., Carslaw, K. S., and Peter, T.: NAT-rock formation by mother clouds: a microphysical model study, Atmos. Chem. Phys., 2, 93-98, 2002.

Fueglistaler, S., Buss, S., Luo, B. P., Wernli, H., Flentje, H., Hostetler, C. A., Poole, L. R., Carslaw, K. S., and Peter, T.: Detailed modeling of mountain wave PSCs, Atmos. Chem. Phys., 3, 697-712, 2003.

Gobiet, A., Foelsche, U., Steiner, A. K., Borsche, M., Kirchengast, G., and Wickert, J.: Climatological validation of stratospheric temperatures in ECMWF operational analyses with CHAMP radio occultation data, Geophys. Res. Lett., 32(12), L12806, doi:10.1029/2005GL022617, 2005.

Goutail, F., Pommereau, J.-P., Lefvre, F., Roozendael, M. V., Andersen, S. B., Høiskar, B. A. K., Dorokhov, V., Kyrö, E., Chipperfield, M. P., and Feng, W.: Early unusual ozone loss during the Arctic winter 2002/2003 compared to other winters, Atmos. Chem. Phys., 5, 665-677, 2005.

Hertzog, A., Vial, F., Dörnbrack, A., Eckermann, S. D., Knudsen, B. M., and Pommereau, J.-P.: In situ observations of gravity waves and comparisons with numerical simulations during the SOLVE/THESEO 2000 campaign, J. Geophys. Res., 107(D20), 8292, doi:10.1029/2001JD001025, 2002.

Höpfner, M.: Study on the impact of polar stratospheric clouds on high resolution mid-IR limb emission spectra, J. Quant. Spectrosc. Radiat. Transfer, 83, 93-107, 2004.

Höpfner, M. and Emde, C.: Comparison of single and multiple scattering approaches for the simulation of limb-emission observations in the mid-IR, J. Quant. Spectrosc. Radiat. Transfer, 91, 275-285, 2004.

Höpfner, M., Oelhaf, H., Wetzel, G., Friedl-Vallon, F., Kleinert, A., Lengel, A., Maucher, G., Nordmeyer, H., Glatthor, N., Stiller, G. P., von Clarmann, T., Fischer, H., Kröger, C., and Deshler, T.: Evidence of scattering of tropospheric radiation by PSCs in mid-IR limb emission spectra: MIPAS-B observations and KOPRA simulations, Geophys. Res. Lett., 29, doi:10.1029/2001GL014443, 2002.

Höpfner, M., Luo, B. P., Massoli, P., Cairo, F., Spang, R., Snels, M., Donfrancesco, G. D., Stiller, G., von Clarmann, T., Fischer, H., and Biermann, U.: Spectroscopic evidence for NAT, STS, and ice in MIPAS infrared limb emission measurements of polar stratospheric clouds, Atmos. Chem. Phys., 6, 1201-1219, 2006.

Hu, R., Carslaw, K. S., Hostetler, C., Poole, L. R., Luo, B., Peter, T., Füeglistaler, S., McGee, T. J., and Burris, J. F.: Microphysical properties of wave polar stratospheric clouds retrieved from lidar measurements during SOLVE/THESEO 2000, J. Geophys. Res., 107(D20), 8294, doi:10.1029/2001JD001125, 2002.

Irie, H., Pagan, K. L., Tabazadeh, A., Legg, M. J., and Sugita, T.: Investigation of polar stratospheric cloud solid particle formation mechanisms using ILAS and AVHRR observations in the Arctic, Geophys. Res. Lett., 31(15), L15 107,
doi:10.1029/2004GL020246, 2004

Jiang, J. H., Eckermann, S. D., Wu, D. L., and Ma, J.: A search for mountain waves in MLS stratospheric limb radiances from the winter Northern Hemisphere: Data analysis and global mountain wave modeling, J. Geophys. Res., 109(D3), D03107, doi:10.1029/2003JD003974, 2004.

Knopf, D. A., Koop, T., Luo, B. P., Weers, U. G., and Peter, T.: Homogeneous nucleation of NAD and NAT in liquid stratospheric aerosols: insufficient to explain denitrification, Atmos. Chem. Phys., 2, 207-214, 2002.

Knudsen, B. M. and Grooß, J.: Northern midlatitude stratospheric ozone dilution in spring modeled with simulated mixing, J. Geophys. Res., 105, 6885-6890, 2000.

Larsen, N., Knudsen, B. M., Gauss, M., and Pitari, G.: Aircraft induced effects on Arctic polar stratospheric cloud formation, Meteorol. Z., pp. 207-214, 2002a.

Larsen, N., Svendsen, S. H., Knudsen, B. M., Voigt, C., Weisser, C., Kohlmann, A., Schreiner, J., Mauersberger, K., Deshler, T., Kröger, C., Rosen, J. M., Kjome, N. T., Adriani, A., Cairo, F., Di Donfrancesco, G., Ovarlez, J., Ovarlez, H., Dörnbrack, A., and Birner, T.: Microphysical mesoscale simulations of polar stratospheric cloud formation constrained by in situ measurements of chemical and optical cloud properties, J. Geophys. Res., 107(D20), 8301, doi:10.1029/2001JD000999, 2002b.

Larsen, N., Knudsen, B. M., Svendsen, S. H., Deshler, T., Rosen, J. M., Kivi, R., Weisser, C., Schreiner, J., Mauerberger, K., Cairo, F., Ovarlez, J., Oelhaf, H., and Spang, R.: Formation of solid particles in synoptic-scale Arctic PSCs in early winter 2002/2003, Atmos. Chem. Phys., 4, 2001-2013, 2004.

Luo, B. P., Voigt, C., Fueglistaler, S., and Peter, T.: Extreme NAT supersaturations in mountain wave ice PSCs: A clue to NAT formation, J. Geophys. Res., 108(D15), 4441, doi:10.1029/2002JD003104, 2003

Mann, G. W., Carslaw, K. S., Chipperfield, M. P., Davies, S., and Eckermann, S. D.: Large nitric acid trihydrate particles and denitrification caused by mountain waves in the Arctic stratosphere, J. Geophys. Res., 110(D8), D08202, doi:10.1029/2004JD005271, 2005.

Mengistu Tsidu, G., Stiller, G. P., von Clarmann, T., Funke, B., Höpfner, M., Fischer, H., Glatthor, N., Grabowski, U., Kellmann, S., Kiefer, M., Linden, A., López-Puertas, M., Milz. M., Steck, T., and Wang, D. Y.: $\mathrm{NO}_{y}$ from Michelson Interferometer for Passive Atmospheric Sounding on Environmental Satellite during the Southern Hemisphere polar vortex split in September/October 2002, J. Geophys. Res., 110(D11), D11301, doi:10.1029/2004JD005322, 2005.

Milz, M., von Clarmann, T., Fischer, H., Glatthor, N., Grabowski, U., Höpfner, M., Kellmann, S., Kiefer, M., Linden, A., Mengistu Tsidu, G., Steck, T., Stiller, G. P., Funke, B., López-Puertas, M., and Koukouli, M. E.: Water vapor distributions measured with the Michelson Interferometer for Passive Atmospheric Sounding on board Envisat (MIPAS/Envisat), J. Geophys. Res., 110, D24307, doi:10.1029/2005JD005973, 2005.

Morcrette, J.: Radiation and cloud radiative properties in the European Centre for Medium Range Weather Forecasts forecasting system, J. Geophys. Res., 96, 9121-9132, 1991.

Pagan, K. L., Tabazadeh, A., Drdla, K., Hervig, M. E., Eckermann, S. D., Browell, E. V., Legg, M. J., and Foschi, P. G. Observational evidence against mountain-wave generation of ice 
nuclei as a prerequisite for the formation of three solid nitric acid polar stratospheric clouds observed in the Arctic in early December 1999, J. Geophys. Res., 109(D4), D04312, doi:10.1029/2003JD003846, 2004.

Reichardt, J., Dörnbrack, A., Reichardt, S., Yang, P., and McGee, T. J.: Mountain wave PSC dynamics and microphysics from ground-based lidar measurements and meteorological modeling, Atmos. Chem. Phys., 4, 1149-1165, 2004.

Ricaud, P. D., Carr, E. S., Harwood, R. S., Lahoz, W. A., Froidevaux, L., Read, W. G., Waters, J. W., Mergenthaler, J. L., Kumer, J. B., Roche, A. E., and Peckham, G. E.: Polar stratospheric clouds as deduced from MLS and CLAES measurements, Geophys. Res. Lett., 22, 2033-2036, 1995.

Rivière, E. D., Huret, N., Taupin, F. G., Renard, J.-B., Pirre, M., Eckermann, S. D., Larsen, N., Deshler, T., Lefèvre, F., Payan, S., and Camy-Peyret, C.: Role of lee waves in the formation of solid polar stratospheric clouds: Case studies from February 1997, J. Geophys. Res., 105, 6845-6854, 2000.

Solomon, S., Garcia, R. R., Rowland, F. S., and Wuebbles, D. J.: On the depletion of Antarctic ozone, Nature, 321, 755-758, 1986.

Spang, R., Riese, M., Eidmann, G., Offermann, D., and Wang, P. H.: A detection method for cirrus clouds using CRISTA 1 and 2 measurements, Adv. Space Res., 27, 1629-1634, 2001.

Spang, R., Riese, M., and Offermann, D.: CRISTA-2 observations of the south polar vortex in winter 1997: A new dataset for polar process studies, Geophys. Res. Lett., 28, 3159-3162, 2001.

Spang, R., Eidmann, G., Riese, M., Offermann, D., Preusse, P., Pfister, L., and Wang, P.-H.: CRISTA observations of cirrus clouds around the tropopause, J. Geophys. Res., 107(D23), 8174, doi:10.1029/2001JD000698, 2002.

Spang, R. and Remedios, J. J.: Observations of a distinctive infrared spectral feature in the atmospheric spectra of polar stratopsheric clouds measured by the CRISTA instrument, Geophys. Res. Lett., 30(16), 1875, doi:10.1029/2003GL017231, 2003.

Spang, R., Remedios, J. J., and Barkley, M. P.: Colour indices for the detection and differentiation of cloud types in infra-red limb emission spectra, Adv. Space Res., 33, 1041-1047, 2004.

Spang, R., Remedios, J. J., Kramer, L. J., Poole, L. R., Fromm, M. D., Müller, M., Baumgarten, G., and Konopka, P.: Polar stratospheric cloud observations by MIPAS on ENVISAT: detection method, validation and analysis of the northern hemisphere winter 2002/2003, Atmos. Chem. Phys., 5, 679-692, 2005.

Svendsen, S. H., Larsen, N., Knudsen, B., Eckermann, S. D., and Browell, E. V.: Influence of mountain waves and NAT nucleation mechanisms on polar stratospheric cloud formation at local and synoptic scales during the 1999-2000 Arctic winter, Atmos. Chem. Phys., 5, 739-753, 2005.

Tabazadeh, A.: Commentary on "Homogeneous nucleation of NAD and NAT in liquid stratospheric aerosols: insufficient to explain denitrification" by Knopf et al., Atmos. Chem. Phys., 3, 863$865,2003$.
Tabazadeh, A., Santee, M. L., Danilin, M. Y., Pumphrey, H. C., Newman, P. A., Hamill, P. J., and Mergenthaler, J. L.: Quantifying Denitrification and Its Effect on Ozone Recovery, Science, 288, 1407-1411, 2000.

Tabazadeh, A., Jensen, E. J., Toon, O. B., Drdla, K., and Schoeberl, M. R.: Role of the stratospheric polar freezing belt in denitrification, Science, 291, 2591-2594, 2001.

Tabazadeh, A., Djikaev, Y. S., Hamill, P., and Reiss, H.: Laboratory evidence for surface nucleation of solid solar stratospheric cloud particles, J. Phys. Chem. A, 106, 10 238-10246, 2002.

Tolbert, M. A. and Toon, O. B.: Solving the PSC Mystery, Science, 292, 61-63, 2001.

Toon, O. B., Hammill, P., Turco, R. P., and Pinto, J.: Condensation of $\mathrm{HNO}_{3}$ and $\mathrm{HCl}$ in the winter polar stratospheres, Geophys. Res. Lett., 13, 1284-1287, 1986.

Toon, O. B., Tolbert, M. A., Middlebrook, A. M., and Jordan, J.: Infrared optical constants of $\mathrm{H}_{2} \mathrm{O}$, ice, amorphous nitric acid solutions, and nitric acid hydrates, J. Geophys. Res., 99, $25631-$ 25 654, 1994.

Tsias, A., Wirth, M., Carslaw, K. S., Biele, J., Mehrtens, H., Reichardt, J., Wedekind, C., Weiß, V., Renger, W., Neuber, R., von Zahn, U., Stein, B., Santacesaria, V., Stefanutti, L., Fierli, F., Bacmeister, J., and Peter, T.: Aircraft lidar observations of an enhanced type Ia polar stratospheric clouds during APEPOLECAT, J. Geophys. Res., 104, 23 961-23 970, 1999.

Voigt, C., Schreiner, J., Kohlmann, A., Zink, P., Mauersberger, K., Larsen, N., Deshler, T., Kröger, C., Rosen, J., Adriani, A., Cairo, F., Di Donfrancesco, G., Viterbini, M., Ovarlez, J., Ovarlez, H., David, C., and Dörnbrack, A.: Nitric Acid Trihydrate (NAT) in Polar Stratospheric Clouds, Science, 290, 1756-1758, 2000.

Voigt, C., Larsen, N., Deshler, T., Kröger, C., Schreiner, J., Mauersberger, K., Luo, B., Adriani, A., Cairo, F., Di Donfrancesco, G., Ovarlez, J., Ovarlez, H., Dörnbrack, A., Knudsen, B., and Rosen, J.: In situ mountain-wave polar stratospheric cloud measurements: Implications for nitric acid trihydrate formation, J. Geophys. Res., 108(D5), 8331, doi:10.1029/2001JD001185, 2003.

Voigt, C., Schlager, H., Luo, B. P., Drnbrack, A., Roiger, A., Stock, P., Curtius, J., Vssing, H., Borrmann, S., Davies, S., Konopka, P., Schiller, C., Shur, G., and Peter, T.: Nitric Acid Trihydrate (NAT) formation at low NAT supersaturation in Polar Stratospheric Clouds (PSCs), Atmos. Chem. Phys., 5, 1371-1380, 2005.

Wirth, M., Tsias, A., Dörnbrack, A., Weiß, V., Carslaw, K. S., Leutbecher, M., Renger, W., Volkert, H., and Peter, T.: Model-guided Lagrangian observation and simulation of mountain polar stratospheric clouds, J. Geophys. Res., 104, 23 971-23 982, 1999.

Wu, D. L. and Jiang, J. H.: MLS observations of atmospheric gravity waves over Antarctica, J. Geophys. Res., 107(D24), 4773, doi:10.1029/2002JD002JD002390, 2002. 